\title{
Applicability of Gum Karaya in the Preparation and in Vitro Evaluation of Losartan Potassium as Chronotherapeutic Drug Delivery System
}

\author{
K. Latha ${ }^{* a}$, V. V. Srikanth ${ }^{\mathrm{b}}$, S. A. Sunil ${ }^{\mathrm{b}}$, N. R. Srinivasa ${ }^{\mathrm{b}}$, M. U. Uhumwangho ${ }^{\mathrm{c}}$, N. B. Shaik ${ }^{\mathrm{a}}$ \\ K. V. R. Murthy \\ ${ }^{a}$ G. Pulla Reddy College of Pharmacy, Mehdipatnam, Hyderabad, 500 028, T.S., India \\ ${ }^{\mathrm{b}}$ University College of Pharmaceutical Sciences, Andhra University, Visakhapatnam-530003, A.P., \\ India \\ ${ }^{\mathrm{c}}$ Department of Pharmaceutics and Pharmaceutical Technology, Faculty of Pharmacy, University of \\ Benin, Nigeria
}

Received 28 February 2015, accepted in final revised form 2 April 2015

\begin{abstract}
The objective of this investigation is to study the applicability of gum karaya, the natural gum for the preparation and in vitro evaluation of losartan potassium, as Chronotherapeutic Drug Delivery System (ChDDS). The compression-coated timed-release tablets (CCT) containing losartan potassium in the core tablet were prepared by dry coating technique with different ratios of gum karaya as the outer coat. The parameters investigated were tensile strength, friability, in vitro dissolution studies and drug concentration. The optimized formulation was further characterized by powder XRD and FTIR to investigate interactions and no interactions observed. The tensile strength and friability of all the CCT were between $1.06-1.23 \mathrm{MN} / \mathrm{m}^{2}$ and $<0.3 \%$ respectively. All the CCT showed a clear lag time before a burst release of drug. However, the lag time of drug release increased as the amount of gum karaya in the outer layer increased. For instance, the lag time of LGK1, LGK2, LGK3, LGK4, LGK5, LGK6 and LGK7 were 16, 10.5, 5.5, 3, 2, 1.5 and $0.5 \mathrm{hrs}$ respectively. The drug content of all the CCT was $>98 \%$. Formulation LGK3 was taken as an optimized formulation which can be exploited to achieve ChDDS of losartan potassium for the treatment of hypertension.
\end{abstract}

Keywords: Losartan potassium; Compression coated timed release tablet; Gum karaya; Powder X-ray diffraction; Fourier-Transform Infrared Spectroscopy.

(C) 2015 JSR Publications. ISSN: 2070-0237 (Print); 2070-0245 (Online). All rights reserved. doi: http://dx.doi.org/10.3329/jsr.v7i1-2.21182 J. Sci. Res. 7 (1-2), 65-74 (2015)

\section{Introduction}

Maximum concentration of drug $\left(C_{\max }\right)$ normally reaches within 1-2 hours for many of the conventional dosage forms, which may not match with the maximum intensity of the

* Corresponding author: lathakukatil@gmail.com 
disease state. For effective therapy, it is always advisable to provide maximum drug concentration at maximum intensity of disease condition. Oral time-controlled drug release formulations have the unique characteristic that a drug is released from the formulation after a predetermined lag time before drug release [1]. Time-controlled release formulations could be an effective tool in chronopharmacotherapy because of the drug release is modulated in a manner that the $C_{\max }$ of the drug is reached at the point in the circadian cycle when clinical signs develop or increase. Drugs that treat cardiovascular diseases and asthma have been investigated for the chronopharmacotherapy because these symptoms follow circadian rhythms [2]. Hence, the purpose of this study is to design an optimized Chronotherapeutic Drug Delivery System (ChDDS) of losartan potassium using gum karaya in different ratios with a predetermined lag time [3].

Compression-coated tablets (CCT) are composed of an inner core immediate release tablets that contain an active pharmaceutical ingredient and excipients, surrounded by an outer layer that dissolves or disintegrates slowly to produce the lag time. Advantage of this technique is simple, inexpensive and eco-friendly, since it does not require the high amount of organic solvent.

Losartan potassium is an angiotensin II antagonist. It is used in the treatment of hypertension particularly in diabetic patients for nephropathy. It is a weekly acidic drug with a $\mathrm{pK}_{\mathrm{a}}$ of 4.9 and the biological half life is 2 to $2.5 \mathrm{~h}$ [4]. Adult dose is $25 \mathrm{mg}, 50 \mathrm{mg}$ and $100 \mathrm{mg}$ once daily based on the requirement as prophylactic, treatment and in severe conditions respectively in combination with other antihypertensive drugs.

Gum karaya (GK), also called as Sterculia gum, is the dried exudation of the Sterculia urens tree and other species of Sterculia, which belong to the family Sterculiaceae [5, 6]. GK is a negative colloid and a high-molecular-mass complex acidic polysaccharide. The general utility of GK is based on its viscosity [7]. It was successfully evaluated for its suitability in the preparation of hydrophilic matrices [8], mini-matrices, microcapsules [9] and transdermal patches. The use of hydrophilic polymers as carriers for the dissolution enhancement of poorly water-soluble drugs is increasing [10]. However, the high viscosity [11] and hardness of these polymers might limit their application as carriers for dissolution enhancement.

\section{Experimental}

\subsection{Materials}

Losartan potassium was received as a gift sample from Dr Reddy's Laboratory Pvt. Ltd, Hyderabad, India), Gum karaya was purchased from Girijan co-operative corporation, Visakhapatnam, India. GK is a general food additive and generally recognized as safe (GRAS) in USA since 1961, was accepted temporarily (Annexure 11) as a food additive in 1974. Since then no adverse incident involving human health has been attributed to the ingestion of GK [12]. It has been found that $\mathrm{LD}_{50}$ values of $\mathrm{GK}$ in rats ranged from 2.6 to 
$18.0 \mathrm{~g} / \mathrm{kg}$ [13]. Eastwood found that human subjects could tolerate an oral dosage of 10.5 $\mathrm{g}$ of GK [14].

Avicel 112, croscarmellose sodium (CCS), polylvinylpyrrolidone (PVP K30) were received as gift samples from Aurbindo Pharma Ltd, Hyderabad, India. These were used as diluent, disintegrant and binder respectively, Talc and magnesium stearate (S.D. Fine Chemicals Ltd., Mumbai, India) were used as glidant and lubricant respectively. All other reagents used were of analytical grade. Two different commercial brands (CB)) of immediate release formulations of losartan potassium were purchased from the market. Where P1= ALSARTAN (Manufacturing date: May 2007 and Expiring date April 2010, Aristo Pharmaceuticals Ltd., India) and P2 = COVANCE (Manufacturing date: August 2008 and Expiring date July 2011, Ranbaxy laboratories Ltd., India).

\subsection{Preparation of an optimized core tablet (OCT)}

From preliminary studies in our laboratory, an optimized core tablet was formulated by using various concentrations and different types of diluents, disintegrates and binders. The drug, diluent, disintegrant and binder were weighed for a batch of 100 tablets as per formulae given in Table 1 and were then passed through $500 \mu \mathrm{m}$ sieve, transferred to a polybag and blended for $5 \mathrm{~min}$. To the above homogeneous blend, talc and magnesium stearate was added and blended for $2 \mathrm{~min}$. The resulting blend was compressed with a rotary compression machine (Model Rimek, India) to form a biconvex tablet with a diameter of $6 \mathrm{~mm}$. The weights of the tablets were $106.5 \pm 0.5 \mathrm{mg}$.

Table 1. Optimized core tablet composition.

\begin{tabular}{cc}
\hline Ingredients & Mass $/ \mathrm{tab}(\mathrm{mg})$ \\
\hline Losartan potassium & 50 \\
Avicel 112 & 50 \\
CCS & 2.5 \\
PVP K 30 & 2.5 \\
Magnesium stearate & 0.5 \\
Talc & 1.0 \\
\hline Total mass & 106.5 \\
\hline
\end{tabular}

\subsection{Preparation of compression-coated timed-release tablets (CCT)}

The gum karaya and microcrystalline cellulose (MCC) were accurately weighed as required for a batch of 100 tablets as per formulae given in Table 2 and granulated using $5 \%$ PVP solution in mixture of isopropyl alcohol and water in the ratio of 70:30. Then the wet screening was done by passing through $710 \mu \mathrm{m}$ sieve, and it was dried for $2 \mathrm{~h}$ at $45^{\circ} \mathrm{C}$ in a hot air oven. Then the dried mass was screened. Talc and magnesium stearate were added to the dried granules and passed through $500 \mu \mathrm{m}$ and blended for $2 \mathrm{~min}$. Half the amount of polymer granules was placed into the die to make a powder bed. The core tablet was then placed at the centre on the polymer bed while the remaining half of the polymer granules was filled into the die. The content was compressed with a rotary 
compression machine to form a biconvex tablet with a diameter of $9 \mathrm{~mm}$. The weights of the tablets varied depending on the formulation (Table 2).

Table 2. Coat tablet composition of gum karaya

\begin{tabular}{llllllll}
\hline Ingredients (mg) & LGK1 & LGK2 & LGK3 & LGK4 & LGK5 & LGK6 & LGK7 \\
\hline Gum karaya & 100 & 80 & 60 & 50 & 40 & 20 & 0 \\
MCC & 0 & 20 & 40 & 50 & 60 & 80 & 100 \\
Talc & 1 & 1 & 1 & 1 & 1 & 1 & 1 \\
Magnesium stearate & 0.5 & 0.5 & 0.5 & 0.5 & 0.5 & 0.5 & 0.5 \\
\hline
\end{tabular}

\subsection{Physicochemical analysis of optimized core tablet (OCT), commercial brand (CB) and compression coated tablet (CCT) formulations}

\subsubsection{Friability test}

Ten tablets (1.065 g) were placed in the drum of a friabilator (Electro labs, Model EF2, Mumbai, India) rotating at 100 revolutions for $4 \mathrm{~min}$. The percentage dust formed due to the impact was determined and taken as index of friability. The test was carried in triplicate.

\subsubsection{Disintegration test (DT)}

The method described in the British Pharmacopoeia [15] was followed using water maintained at $37 \pm 2{ }^{\circ} \mathrm{C}$ as the disintegration fluid. Six tablets were placed in disintegration apparatus (Electrolabs, Model, ED-2L Mumbai, India)) for each determination. It was carried out in triplicate and the mean results reported.

\subsubsection{Determination of tablet tensile strength (T)}

This is the stress needed to fracture a tablet by diametral compression. It is given by Fell and Newton [16] as:

$$
\mathrm{T}=2 \mathrm{P} / \pi \mathrm{Dt}
$$

Where, $P$ is the fracture load that causes tensile failure of a tablet of diameter, $D$ and thickness, $t$. The fracture load $(\mathrm{kg})$ of ten tablets was determined individually with the Monsanto hardness tester (Tab Machines, Mumbai, India), following Brook and Marshal [17]. The mean values of the fracture loads were used to calculate the $T$ values for the various tablets.

\subsection{In vitro drug release studies for OCT, CB formulations and CCT}

The OCT and two different $\mathrm{CB}$ formulations were subjected to in vitro drug release in a $900 \mathrm{~mL}$ of $6.8 \mathrm{pH}$ phosphate buffer for $90 \mathrm{~min}$. On the other hand, the different coated 
tablets with varying ratios of polymer coating were subjected to in vitro drug release studies in different suitable dissolution media for $24 \mathrm{~h}$ to assess their ability in providing the desired lag time before drug release. The in vitro drug release studies were performed using a USP Type I dissolution apparatus. The dissolution medium for the first two $\mathrm{h}$ was $900 \mathrm{~mL}$ of $0.1 \mathrm{~N} \mathrm{HCl}$ for the remaining period $6.8 \mathrm{pH}$ phosphate buffer was used. The temperature of dissolution medium was maintained at $37 \pm 0.2^{\circ} \mathrm{C}$. The tablet was introduced into the basket and was rotated at $50 \mathrm{rpm}$. In all experiments, an aliquot of 5 $\mathrm{mL}$ sample was withdrawn at predetermined time intervals and replaced with an equal volume of the fresh dissolution medium to maintain the sink condition. The samples were filtered and analyzed spectrophotometrically at $\lambda_{\max }$ of $230 \mathrm{~nm}$ for the percentage drug release. One tablet was used for each determination and the experiment was performed in triplicates.

\subsection{Drug concentration of the OCT, CB formulations and CCT}

In order to determine the concentration of losartan potassium present in all the tablets, 5 tablets were weighed and crushed to fine powder. The powder equivalent to $50 \mathrm{mg}$ of drug was weighed out. The equivalent weight of drug was transferred into a $100 \mathrm{~mL}$ of volumetric flask and diluted with $6.8 \mathrm{pH}$ phosphate buffer, the resulting solution was filtered. $1 \mathrm{~mL}$ was taken and diluted 10 times with $6.8 \mathrm{pH}$ phosphate buffer. The absorbance of the resulting solution was measured at $230 \mathrm{~nm}$ and the drug concentration in the tablets was estimated from the regression equation.

\subsection{Compatibility studies}

Physical and chemical interaction or complexation throughout the formulation and compression process was carried out by the PXRD and FTIR.

\subsubsection{Powder X-ray diffraction (PXRD)}

PXRD was performed using a type D/Max-2400 diffractometer (Rigaku Instrument, Japan). The samples were exposed to CuKa radiation at $56 \mathrm{kV}$ and $182 \mathrm{~mA}$ over the $2 \theta$ range from $3^{\circ}$ to $45^{\circ}$ in increments of $0.5^{\circ} / \mathrm{min}$ every $0.04^{\circ}$.

\subsubsection{Fourier Transform Infra Red (FTIR) spectroscopy}

The FTIR spectra of the different samples were recorded in an Infra Red spectrometer (Shimadzu, Japan) using $\mathrm{KBr}$ discs prepared from powdered samples. The spectrum was recorded in the region of 4000 to $400 \mathrm{~cm}^{-1}$. 


\section{Results and Discussions}

\subsection{Physicochemical parameters of the OCT, CB formulations and CCT of losartan potassium}

\subsubsection{Friability, hardness, disintegration time and drug content}

The results of the friability, tensile strength and disintegration test for OCT and the two $\mathrm{CB}$ of losartan potassium are presented in Table 3. Friability index is a measure of the ability of the tablet to withstand abrasion during packaging, handling and transportation. It was observed that the friability values for the OCT and the two $\mathrm{CB}$ formulations were $<$ $0.6 \%$ while their tensile strength values were between $1.06-1.23 \mathrm{MN} / \mathrm{m}^{2}$. However, there was no significant difference between these values ( $>0.05$ ). The DT values for the OCT and the two $\mathrm{CB}$ were less than $2 \mathrm{~min}$. as against the stipulated official time of $15 \mathrm{~min}$. (BPC 2002). More so, their drug concentrations were $>97 \%$ (Table 3).

Table 3. Physico-chemical parameters of core tablet and commercial tablets.

\begin{tabular}{cccc}
\hline Formulations & Optimized core tablet & $\mathrm{P} 1$ & $\mathrm{P} 2$ \\
\hline Drug concentration $^{\mathrm{a}}(\%)$ & $99.1 \pm 1.5$ & $99.3 \pm 0.35$ & $99.0 \pm 0.13$ \\
Tensile strength $^{\mathrm{b}}\left(\mathrm{MNm}^{-2}\right)$ & $1.06 \pm 0.2$ & $1.23 \pm 0.37$ & $1.23 \pm 0.25$ \\
Friability $^{\mathrm{c}}(\%)$ & $0.42 \pm 0.05$ & $0.5 \pm 0.07$ & $0.5 \pm 0.05$ \\
Disintegration time $^{\mathrm{d}}(\mathrm{s})$ & $20 \pm 0.02$ & $90 \pm 0.4$ & $85 \pm 1.0$ \\
\hline a: mean \pm s.d., $\mathrm{n}=5 ;$ b: mean \pm s.d., $\mathrm{n}=5 ;$ c: mean \pm s.d., $\mathrm{n}=10 ;$ d: mean \pm s.d., $\mathrm{n}=6$
\end{tabular}

Table 4. Physico-chemical parameters of compression coated tablets.

\begin{tabular}{|c|c|c|c|c|c|c|c|}
\hline Formulations & LGK1 & LGK2 & LGK3 & LGK4 & LGK5 & LGK6 & LGK7 \\
\hline $\begin{array}{c}\text { Drug } \\
\text { concentration }^{\mathrm{a}} \\
(\%)\end{array}$ & $101.1 \pm 1.5$ & $99.8 \pm 1.1$ & $101.5 \pm 0.9$ & $99.8 \pm 0.60$ & $100.5 \pm 0.55$ & $98.9 \pm 1.40$ & $100.6 \pm 1.20$ \\
\hline $\begin{array}{l}\text { Tensile } \\
\text { strength }^{\mathrm{b}} \\
\left(\mathrm{MN} / \mathrm{m}^{2}\right)\end{array}$ & $1.06 \pm 0.5$ & $1.14 \pm 0.10$ & $1.23 \pm 0.15$ & $1.06 \pm 0.70$ & $1.14 \pm 0.30$ & $1.14 \pm 0.25$ & $1.23 \pm 0.55$ \\
\hline Friability $^{\mathrm{c}}(\%)$ & $0.28 \pm 0.01$ & $0.11 \pm 0.05$ & $0.12 \pm 0.06$ & $0.2 \pm 0.02$ & $0.26 \pm 0.05$ & $0.17 \pm 0.02$ & $0.19 \pm 0.05$ \\
\hline Lag time $^{\mathrm{d}}(\mathrm{h})$ & $16.0 \pm 0.33$ & $10.5 \pm 0.57$ & $5.5 \pm 0.25$ & $3.0 \pm 0.67$ & $2.0 \pm 0.33$ & $1.5 \pm 0.57$ & $0.5 \pm 0.33$ \\
\hline
\end{tabular}

On the other hand the friability, hardness and drug content values for all the CCT (LGK1 to LGK7) are shown in Table 4. It was observed that the friability values were < $0.3 \%$ while their hardness values were between $1.06-1.23 \mathrm{MN} / \mathrm{m}^{2}$. There was also no statistically significant difference between these values $(\mathrm{p}>0.05)$. The drug content values for all the CCT were $>98 \%$. 


\subsection{Drug release profile for the OCT and the two CB of losartan potassium}

The drug release profiles of the OCT and the two CB of losartan potassium are presented in Fig. 1. The release parameters obtained from these curves are also shown in Table 5. However, it can be observed that OCT gave a comparable release profile with the two CB. The value of the release parameters for OCT and the two CB (P1 and P2) are maximum release $\left(m_{\infty}\right), 93 \%, 84 \%$ and $79 \%$ respectively, while the time to attain maximum release $\left(t_{\infty}\right)$ was the same for all the formulations (i.e. $45 \mathrm{~min}$ ). However, the dissolution rate $\left(m_{\infty} / t_{\infty}\right)$ was observed to be $2.01,1.87,1.76 \mathrm{~min}^{-1}$ for OCT, P1 and P2 respectively.

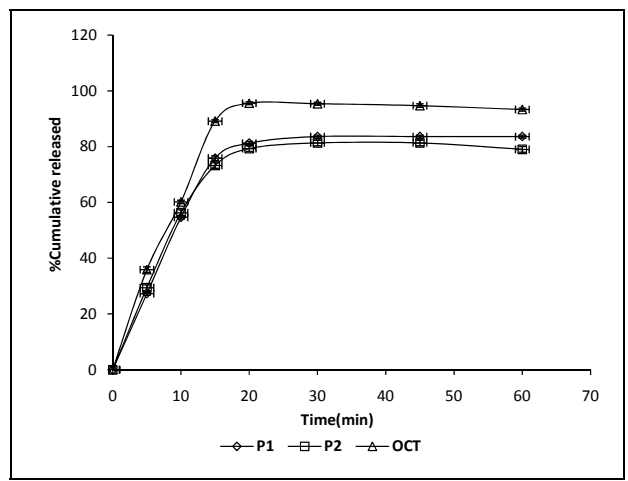

Fig. 1. Cumulative percentage of losartan potassium released from different tablets from phosphate buffer $\mathrm{pH}(6.8)$ where OCT is core tablet, $\mathrm{P} 1$ is Alsartan and P2 is Covance.

Table 5. Dissolution parameters $\left\{\mathrm{m}_{\infty}(\%), \mathrm{t}_{\infty}(\mathrm{min}), \mathrm{m}_{\infty} / \mathrm{t}_{\infty}\left(\% \mathrm{~min}^{-1}\right)\right\}$ for OCT and two CB

\begin{tabular}{cccc}
\hline $\begin{array}{c}\text { Different } \\
\text { Formulations }\end{array}$ & $\begin{array}{c}\text { Optimized } \\
\text { core tablet }\end{array}$ & $\mathrm{P} 1$ & $\mathrm{P} 2$ \\
\hline $\mathrm{m}_{\infty}(\%)$ & 93 & 84 & 79 \\
$\mathrm{t}_{\infty}(\mathrm{min})$ & 45 & 45 & 45 \\
$\mathrm{~m}_{\infty} / \mathrm{t}_{\infty}\left(\% \mathrm{~min}^{-1}\right)$ & 2.01 & 1.87 & 1.76 \\
\hline
\end{tabular}

\subsection{Drug release profile for all the formulated CCT of losartan potassium}

The drug release profiles of all the formulated CCT (LGK1-L GK7) of losartan potassium are presented in Fig. 2. All the formulations had different lag times followed by a burst release of the losartan potassium. It was observed that the lag time for drug release from the compression coated tablets was increased as the concentration of the gum karaya: MCC was increased in the outer coat. For instance, at a polymer ratio of 100:0 (LGK1), 80:20 (LGK2), 60:40 (LGK3), 50:50 (LGK4), 40:60 (LGK5), 20:80 (LGK6) and as well as 0:100 (LGK7) their corresponding lag time values were $16,10.5,5.5,3,2,1.5$ and 0.5 h. There was a statistically significant difference between the lag time as the coating polymer increased $(\mathrm{p}<0.05)$. Previously, Katikaneni et al., [18] had reported that increase in tablet tensile strength is accompanied by a decrease in release rate, due to a decrease in 
tablet porosity [18]. However, since there is no significant change in the tablet tensile strength of all the CCT formulations with increased concentration of the gum karaya as compression coating material (Table 4), hence the lag time of losartan potassium before burst release may not be due to tablet tensile strength. It may be attributable to the different ratio of the polymer coating used as outer layer for the preparation of the compression coated tablets.

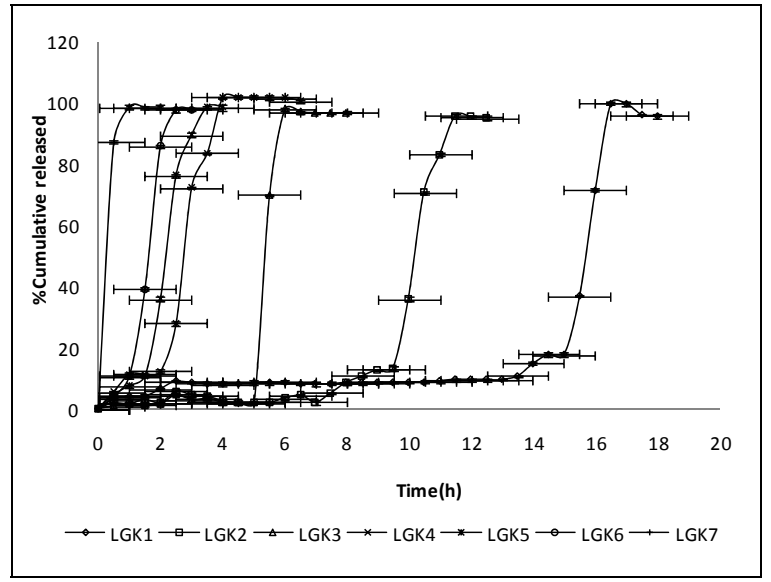

Fig. 2. Dissolution profile of the different compression coated tablets formulated with different ratios of karaya gum polymer as coating agent.

\subsection{Powder $X$-ray diffraction}

The powder X-ray diffraction patterns of the drug and excipients as well as the OCT are presented in Fig. 3. In spite of a series of smaller peaks, losartan potassium has distinct crystalline peaks at $2 \theta$ angles of $10.8^{\circ}, 13.6^{\circ}, 18.5^{\circ}$ and $24.2^{\circ}$ (Fig. 3a). However, in the gum karaya the intensity was markedly reduced which show that it was amorphous (Fig. 3b). These peaks were seen at the same position in the OCT (Fig. 3c). These observations concluded that no physical interaction between drug and polymer as well as the crystalline nature of the drug was unaltered.

\subsection{Fourier Transform Infra Red spectroscopy}

The FTIR spectra of the losartan potassium, gum karaya and the OCT are shown in Fig. 4. The characteristic $-\mathrm{C}-\mathrm{O}-\mathrm{C}$ stretch for losartan potassium at $1006 \mathrm{~cm}^{-1},-\mathrm{C}-\mathrm{Cl}$ at 1259,1357 $\mathrm{cm}^{-1},-\mathrm{C}=\mathrm{C}$ stretch at $1605,1494,1460 \mathrm{~cm}^{-1},-\mathrm{N}=\mathrm{N}$ stretch at $1576 \mathrm{~cm}^{-1},-\mathrm{C}-\mathrm{H}$ stretch at $2871,2929,2956 \mathrm{~cm}^{-1}$ and $-\mathrm{O}-\mathrm{H}$ stretch at $3205 \mathrm{~cm}^{-1}$ are observed. For gum karaya the characteristic alcoholic stretch at $3450 \mathrm{~cm}^{-1},-\mathrm{C}=\mathrm{O}$ stretch peaks at $1731 \mathrm{~cm}^{-1},-\mathrm{C}=\mathrm{CH}_{2}$ at $1620 \mathrm{~cm}^{-1}$, -C-O-C- asymmetric at $1254 \mathrm{~cm}^{-1}$, symmetric at $1042 \mathrm{~cm}^{-1}$ due to acetyl groups of karaya polysaccharide are appeared. The absorptions at 1616 and $1423 \mathrm{~cm}^{-1}$ are 
due to carboxylate groups of the uronic acid residues. All the characteristic peaks observed for both drug and excipient remained unchanged in LGK3. This observation ruled out the possibility of chemical interaction and complex formation between the losartan potassium and added excipient (such as gum karaya) during the production process.

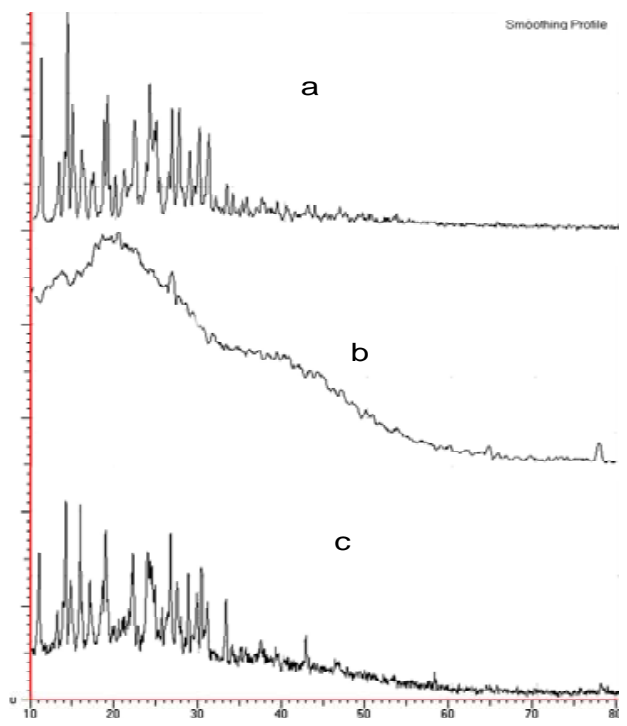

Fig. 3. Powder X-ray diffraction patterns of (a) losartan potassium (b) gum karaya and (c) CCT.

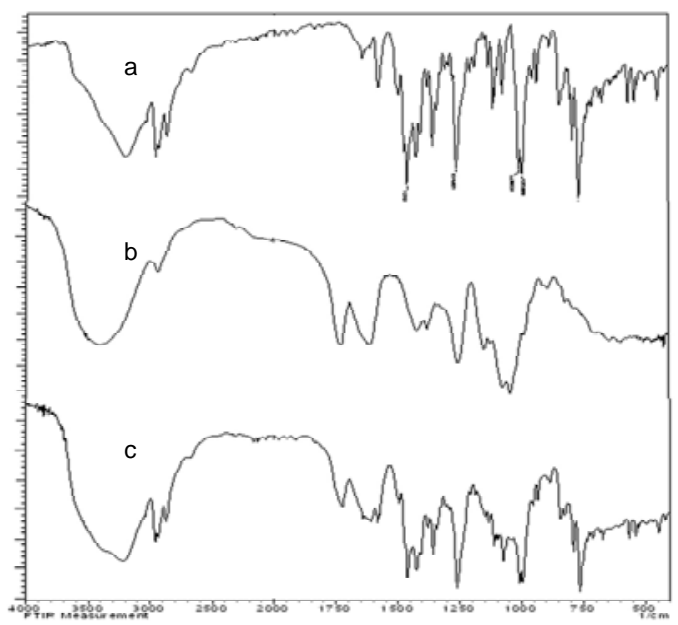

Fig. 4. FTIR of (a) Losartan potassium (b) gum karaya and (c) CCT. 


\section{Conclusions}

Optimized chronotherapeutic drug delivery systems of losartan potassium using gum karaya with the ratio of 60:40 (gum karaya: MCC) has been developed. Formulation LGK3 with a predetermined lag time of $6 \mathrm{~h}$ before burst release of the drug from a press coated tablet was taken as the optimized formulation and it was observed that no modification and/ or chemical interaction throughout the process of formulation. Hence from the above study it was concluded that gum karaya is suitable for the development of chronotherapeutic drug delivery systems with losartan potassium.

\section{References}

1. T. Sawada, K. Sako, K. Yoshihara, K. Nakamura, S. Yokohama, and M. Hayashi, J.Pharm. Sci. 92, 790 (2003). http://dx.doi.org/10.1002/jps.10336

2. B. Lemmer, J. Control.Rel, 19, 63 (1991). http://dx.doi.org/10.1016/0168-3659(91)90031-8

3. B.M. Rahman, M.A. Islam, M.I.I. Wahed, M. Ahmed, R. Islam, R.K. Barman, A.S.M. Anisuzzaman, and P. Khondkar, J. Sci. Res. 1, 353 (2009).

4. W. Martindale, The Extra Pharmacopoeia, $31^{\text {st }}$ Edition (The Pharmaceutical Press, London 1996). pp. 427.

5. A.M. Goldstein, E.W. Alter, and G. karaya, Industrial Gums, ed. R.L. Whistler et al. (Academic Press, New York, 1973) pp. 273.

6. L. Kukati, K. Chittimalli, and N. B. Shaik, J. Sci. Res. 6, 563 (2014). http://dx.doi.org/10.3329/jsr.v6i3.18339

7. S.D. Gershon and M. Pader, Cosmetics Science and Technology, ed. M.S. Balsam et al. $2^{\text {nd }}$ Edition, (Wiley-Interscience, New York, 1972) 1, pp. 423.

8. G.V. Murali, M. Babu, K. Himasankar, C.P.S. Narayan, and K.V. R. Murthy, Acta Pharma. 51, $273(2001)$.

9. N.K. Jain, K. Kulkarni, and N. Talwar, Pharmazie 47, 277 (1992).

10. K. Okimoto, M. Miyake, R. Ibuki, M. Yasumura, N. Ohni-shi, and T. Nakai, Int. J. Pharm. 159, 85 (1997). http://dx.doi.org/10.1016/S0378-5173(97)00274-3

11. C. Portero, L. Remunan and J.L.V. Jata, Int. J. Pharm, 175, 75 (1998). http://dx.doi.org/10.1016/S0378-5173(98)00245-2

12. G.U. Ochuba and R. Von, Appl. Environ. Micribial. 39, 988 (1980).

13. A.A. Salyers, J.R. Vercellotti, S.E.H. West, and T.D. Wilkings, Appl. Environ. Micribial. 33, 319 (1977).

14. D.M.W. Anderson, Food addit. Contam. 6, 189 (1989). http://dx.doi.org/10.1080/02652038909373774

15. British Pharmacopoeia. Monograph on Disintegration Times of Uncoated Tablets (Her Majestyis Stationery Office, London, 2002) A237.

16. J.T. Fell and J.M. Newton, J. Pharm. Sci. 59, 688 (1970). http://dx.doi.org/10.1002/jps.2600590523

17. D.B. Brook and M. Marshall, J. Pharm. Sci. 57, 481 (1968). http://dx.doi.org/10.1002/jps.2600570326

18. P.R. Katikaneni, S.M. Upadrashta, S.H. Neau, and A.K. Mitra, Int. J. Pharm. 123, 119 (1995). http://dx.doi.org/10.1016/0378-5173(95)00060-V 